\title{
Pro-Inflammatory Gene Expression in Adipose Tissue of Patients With Atherosclerosis
}

\section{S. ČEJKOVÁ ${ }^{1}$, I. KRÁLOVÁ LESNÁ ${ }^{1}$, J. FRONĚK ${ }^{2}$, L. JANOUŠEK ${ }^{2}$, A. KRÁLOVÁ ${ }^{1}$, J. ŽDYCHOVÁ ${ }^{3}$, F. THIEME ${ }^{2}$, R. POLEDNE ${ }^{1}$}

${ }^{1}$ Laboratory for Atherosclerosis Research, Institute for Clinical and Experimental Medicine, Prague, Czech Republic, ${ }^{2}$ Centre for Experimental Medicine, Department of Transplant Surgery, Institute for Clinical and Experimental Medicine, Prague, Czech Republic, ${ }^{3}$ Department of Clinical and Transplant Immunology, Institute for Clinical and Experimental Medicine, Prague, Czech Republic

Received March 21, 2016

Accepted February 7, 2017

On-line April 12, 2017

\section{Summary}

Inflammatory changes, both in the arterial wall and adipose tissue, play a crucial role in the development of atherosclerosis. We measured the gene expression of tumor necrosis factor-alpha (TNFa), monocyte chemoattractant protein-1 (MCP-1), and interleukin 6 (IL-6) in adipose tissue (AT) of living kidney donors (LKD) and patients with peripheral arterial disease (PAD). Quantitative polymerase chain reaction (qPCR) and flow cytometry analyses were performed in subcutaneous (SAT), visceral (VAT), and perivascular adipose tissue (PVAT). Data of PAD patients showed significantly higher expression in VAT in all three genes (TNFa 5-fold, $p<0.05$; MCP-1 3.6-fold, $p<0.05$; IL-6 18.8-fold, $p<0.001$ ). The differences in PVAT and SAT were less significant. Total body pro-inflammatory status was documented by higher TNFa concentration in patients (4.86 \pm $1.4 \mathrm{pg} / \mathrm{ml})$ compared to LKDs $(2.14 \pm 0.9 \mathrm{pg} / \mathrm{ml} ; \mathrm{p}<0.001)$, as was hsCRP (11.8 \pm 7.0 in PAD; $1.5 \pm 0.48$ in LKDs; $p=0.017$ ). We found no age-dependent relationship between gene expression vs. TNFa and hsCRP concentrations in both compared groups. No effect of the atherosclerosis score on gene expression and circulating inflammatory markers within the PAD group was observed. Our results suggest that the AT of PAD patients infiltrated with macrophages produces more cytokines involved in the development of inflammation and atherosclerosis.

\section{Key words}

Atherosclerosis • Adipose tissue • Gene expression

\section{Corresponding author}

R. Poledne, Institute for Clinical and Experimental Medicine (IKEM), Vídeňská 1958/9, 14021 Prague 4, Czech Republic. E-mail: rupo@ikem.cz

\section{Introduction}

Adipose tissue (AT) inflammation is typical for insulin resistance and dyslipidemia triggering atherogenic subclinical inflammation (Alexopoulos et al. 2014). Traditionally, AT is distributed into two main different deposits: subcutaneous AT (SAT) and visceral AT (VAT). Although abdominal obesity was implicated as a risk factor of diabetes and atherosclerosis development as early as the 1950s (Vague 1956), its role in these processes is still not fully understood. The extent of endocrine, paracrine, and autocrine activities involved in atherosclerosis development was first described in the 1990s (Funahashi et al. 1999). These activities do not only occur in adipocytes but, also, take the form of macrophages infiltrating AT (Suganami and Ogawa 2010, Chawla et al. 2011), which may be a link between obesity and development of cardiovascular disease. Adipose tissue produces a variety of pro- and anti-inflammatory bioactive substances, such as monocyte chemoattractant protein 1 (MCP-1), leptin, adiponectin, interleukins (IL-1, IL-6, IL-8, etc.), and tumor necrosis factor-alpha (TNF $\alpha)$ (Sopasakis et al. 2005). 
Not only the number of infiltrated macrophages but also the imbalance between pro- and anti-inflammatory phenotypes of macrophages might be involved in the risk of developing pro-inflammatory status and, subsequently, risk of developing cardiovascular disease (Ridker et al. 1997). Cytokines released from macrophages stimulate monocyte/ macrophage infiltration and contribute to further cytokine production. All these changes induce inflammatory status of the body.

In general, VAT is considered to have a higher impact on pro-atherogenic changes, as it correlates with higher oxidative stress, chronic low-grade inflammation, and insulin resistance (Fox et al. 2007, Pou et al. 2007). Likewise, VAT is more infiltrated by macrophages (Jonas et al. 2015), which contributes to the more prominent inflammatory changes compared to SAT. Perivascular AT (PVAT) is a special subtype of VAT that surrounds blood vessels. While this type of VAT was long considered only a connective tissue supporting blood vessels, it has been recently suggested it might play a direct role in atherosclerotic plaque formation (Chang et al. 2013, Britton et al. 2012, Brown et al. 2014). Similar to VAT, PVAT produces many cytokines, including MCP-1, TNFa, IL-6, and IL-8. In addition, paracrine activity can have an effect on vessels; however, studies are conducted mostly in animal models (Brown et al. 2014).

This study focuses on comparisons of the pro-inflammatory gene expression in SAT, VAT and PVAT of patients with atherosclerosis (documented by angiography of the peripheral arteries) to healthy living kidney donors (LKDs). Out of the many potential genes that contribute to the inflammatory environment in AT, we focused on three cytokines: TNF $\alpha$, MCP-1, and IL-6. $\mathrm{TNF} \alpha$ is one of the most important pro-inflammatory cytokines (Kleinbongard et al. 2010), MCP-1 contributes mainly to monocyte adhesion and tissue infiltration (Kanda et al. 2006, Suganami and Ogawa 2010) whereas IL-6 is involved predominantly in lipid metabolism (Litvinova et al. 2014, Sadashiv et al. 2015) and is considered the most important player in inflammatory processes. Cytokine production of adipocytes and preadipocytes (Zdychova et al. 2012) is probably influenced by infiltrated macrophages. Given the above facts, we analyzed gene expression together with macrophage infiltration in both studied groups.

\section{Methods}

Adipose tissue was obtained intraoperatively either from LKDs during kidney transplantation, or during peripheral arterial tree reconstruction in patients with angiographically documented peripheral arterial disease (PAD). Visceral AT and PVAT of LKDs were obtained during cleansing of isolated kidney (VAT from the area outside Gerota's fascia, PVAT surrounding the renal artery). Similarly, these samples were obtained intraoperatively in the patient group (with the exception of $30 \%$ of PVAT obtained from periaortic AT). Subcutaneous AT was obtained from similar sites in both groups.

All healthy LKDs and patients scheduled for arterial tree reconstruction were informed about the study in detail and signed informed consent forms. The study was approved by the Institute's Ethics Committee.

Stromal vascular fractions of SAT, VAT, and PVAT were isolated for macrophage analysis by flow cytometry. The stromal vascular fraction was separated using a procedure which was in accordance with Zuk et al. (2001) with a minor modification. Briefly, all visible blood vessels and connective tissues were removed and cut into small pieces $(2 \mathrm{~mm})$. About $2 \mathrm{~g}$ of the AT obtained was exposed to collagenase (c=0.002 g/ml; Sigma-Aldrich, St. Louis, MO, USA) and then repeatedly filtered and purified. The obtained stromal vascular fractions were analyzed on the same day using a CyAn ADP 9C flow cytometer using the Kaluza software (Beckman Coulter, Brea, CA, USA) and monoclonal antibody (CD14 - Phycoerythrin-(PE)cyanine 7, Beckman Coulter, Brea, CA, USA) was used to identify monocytes/macrophages. The number of CD14+ monocytes/macrophages per gram of the AT used was finally counted.

Luminex performance assays (R\&D Systems Inc., Minneapolis, MN, USA) were used to measure cytokine concentrations in blood plasma samples of the LKDs and PAD patients. The Luminex assay is a multiplex bead-based immunoassay, which allows for simultaneous measurement of multiple analytes using a library of antibody-coupled color-coded beads. The analysis was done according to the manufacturer's instructions. Plates were read using a Luminex 100 analyzer (PerkinElmer Life Inc., Boston, MA, USA) and xPONENT software (Luminex, Austin, TX, USA). The Mann-Whitney test was used for statistical analysis. High-sensitivity C-reactive protein (hsCRP) was 
measured using an immunoturbidimetric assay with an autoanalyzer (Cobas Mira Plus, Roche, Basel, Switzerland).

Using common criteria and a scoring system, PAD patients were stratified into three groups (A, B, C) based on the severity of stenosis or clog/blockage of the aorta, common iliac artery, and external iliac artery (Hardman et al. 2014). Our PAD group was then divided into two subgroups only, $\mathrm{A}$ and $\mathrm{B}$, as only 2 individuals were assigned to group $\mathrm{C}$; hence our analysis subsequently involved two groups with arteries showing mild or severe involvement.

Samples for gene expression analysis were frozen immediately in liquid nitrogen. Total RNA was isolated from the whole visceral, perivascular and subcutaneous adipose tissue of LKDs and patients with angiographically documented atherosclerosis. Approximately $200 \mathrm{mg}$ of each tissue was used for total RNA extraction with TRIzol Reagent (Molecular Research Centre, Cincinnati, OH, USA). 100 ng of total isolated RNA was used for reverse transcription. After DNase I (Sigma Aldrich, St. Louis, MO, USA) treatment to eliminate DNA from the RNA preparations, cDNA was generated according to the manufacturer's instructions using the High Capacity RNA-to-cDNA Master Mix kit (Life Technologies, Carlsbad, CA, USA). Levels of gene expression of the cytokines and adipokines of interest were subsequently determined on the Corbett Life Science Rotor Gene 3000 (Qiagen, Venlo, The Netherlands) using the QuantiTect SYBR Green PCR Kit (Qiagen, Venlo, The Netherlands). The nucleotide sequences of the primer pairs of TNF $\alpha$ (tumor necrosis factor $\alpha$, NM_000594.3), MCP-1 (CCL2, C-C motif chemokine ligand 2, NM_002982.3) and IL-6 (Interleukin 6, NM_000600.4) used in the study are given in Table 1. Beta-2-microglobulin (B2M, NM_004048.2) levels were used as endogenous controls for normalization.

Relative gene expression was calculated using the $\Delta \Delta \mathrm{Ct}$ method (Pfaffl 2001) compared to the appropriate AT. The Kruskal-Wallis test with Dunn's post multiple comparison test was used for statistical analysis of differences between the groups compared, the Mann-Whitney test for two-group comparison, and the Friedman test for paired comparisons. The results were considered statistically significant with a $\mathrm{p}<0.05$.

Table 1. Nucleotide sequences of primer pairs used in this study.

\begin{tabular}{|c|c|c|}
\hline Gene of interest & Forward primer sequence $\left(5^{\prime}-3^{\prime}\right)$ & Reverse primer sequence $\left(5^{\prime}-3^{\prime}\right)$ \\
\hline$I L-6$ & AGCAGCAAAGAGGCACTGGCA & GCACAGCTCTGGCTTGTTCCTCA \\
\hline$M C P-1$ & AGAAGCTGTGATCTTCAAGACC & AGCTGCAGATTCTTGGGTTG \\
\hline$T N F \alpha$ & CTCTGGCCCAGGCAGTCAGATCA & GGGCAGCCTTGGCCCTTGAA \\
\hline Beta-2-microglobulin & TCTCTCTTTCTGGCCTGGAG & AATGTCGGATGGATGAAACC \\
\hline
\end{tabular}

Table 2. Characteristics of the analyzed populations.

\begin{tabular}{lccc}
\hline & $\begin{array}{c}\text { Living kidney donors } \\
(\mathbf{n = 3 5 )}\end{array}$ & $\begin{array}{c}\text { Patients with PAD } \\
(\mathbf{n = 2 4 )}\end{array}$ & Significance \\
\hline Age (years) & $46 \pm 10.5$ & $61 \pm 12.9$ & $\mathrm{p}<0.0001$ \\
BMI & $26.3 \pm 3.8$ & $27.4 \pm 4.8$ & $\mathrm{p}=0.489$ \\
Smoker, $n(\%)$ & $10(28.6 \%)$ & $19(79.2 \%)$ & $\mathrm{p}<0.0001$ \\
Hypertension, $n(\%)$ & $9(25.7 \%)$ & $19(79.2 \%)$ & $\mathrm{p}<0.0001$ \\
Diabetes type 2, $n(\%)$ & $0(0 \%)$ & $7(29.2 \%)$ & $\mathrm{p}<0.001$ \\
\hline
\end{tabular}

\section{Results}

When comparing the characteristics of the group of PAD patients and that of healthy LKDs (Table 2), it was evident that the patients were significantly older compared to LKDs. To analyze this possible limitation, we compared individuals below and over 50 years of age in all parameters analyzed within the LKDs group and 
found no significant differences when younger and older subgroups were compared in all three gene expression categories as well as in intra-vassal inflammatory marker concentrations. Living kidney donors were slightly leaner but this difference was not statistically significant. It is understandable that the prevalence of smoking as well as that of hypertension and type 2 diabetes was substantially higher in patients with proven atherosclerosis compared to healthy donors. The prevalence of smoking in the group of patients with PAD was almost three times, and the prevalence of hypertension more than twice that compared to LKDs. Only one living kidney donor had a higher fasting glucose concentration ( $>7 \mathrm{mmol} / \mathrm{l})$, but the presence of diabetes was not clinically confirmed. It should be noted that the main difference was observed in the prevalence of smoking so the fact that almost all patients were smokers may have played an important role in this finding.

The concentration of TNF $\alpha$ in blood plasma was significantly higher $(4.86 \pm 1.4 \mathrm{pg} / \mathrm{ml})$ in the PAD group compared to LKDs $(2.14 \pm 0.9 \mathrm{pg} / \mathrm{ml})$ with a high level of significance $(\mathrm{p}<0.001)$. A similar pattern was found in hsCRP levels between the groups $(11.79 \pm 7.0$ in PAD and $1.5 \pm 0.48$ in LKD), but the significance was rather small $(p=0.017)$ because of high variation in both groups. The concentration of IL-6 was also higher in the PAD group, but this parameter was under the sensitivity limit of the method in the majority of LKDs $(0.54 \mathrm{pg} / \mathrm{ml})$. In agreement with accelerated pro-inflammatory status of patients compared to LKDs, measured by hsCRP concentration, also concentration of both proinflammative cytokines (TNF $\alpha$, IL-6) was higher in PAD patients.

As the production of cytokines whose expression was analyzed is supposed to be predominantly in macrophages settled in the AT, their number per gram of each type of AT was analyzed and compared between LKDs and the PAD patient group. There was no significant difference in the number of macrophages (CD14+) of the groups compared in VAT (11001 \pm 10351 in LKDs, and $11457 \pm 12462$ in PAD patients) as well as in PVAT $(11494 \pm 12347$ in LKDs and $15500 \pm 13222$ in PAD patients). The only difference of borderline significance was found in SAT (7411 \pm 8527 in LKDs and $20721 \pm 23312$ in PAD patients). It is necessary to stress that the number of macrophages in any AT did not play a substantial role in the analyzed gene expression. A quite high variation in the number of macrophages per gram in each of the compared groups was found.
All of the data related to gene expression are presented in Figures 1, 2 and 3. Generally, the expression of all the analyzed genes tended to be higher in the PAD group compared to LKDs. Only the VAT of the PAD group showed significantly higher expression in all three genes analyzed (TNF $\alpha$ 5-fold, $\mathrm{p}<0.05$; MCP-1 3.6-fold, $\quad \mathrm{p}<0.05$; IL-6 18.8-fold, $\mathrm{p}<0.001$ ). Only TNF $\alpha$ gene expression in the PVAT of PAD patients was significantly higher compared to LKDs (4.6-fold, $\mathrm{p}<0.01$ ) whereas no other differences between the groups compared were statistically significant. We found no difference of gene expression in SAT.

When the LKD group was divided into subgroups of below and over 50 years of age, no difference was seen in gene expression. Despite a significant difference in age between LKDs and PAD patients, it is most unlikely that this fact might have played an important role in gene expression of the two groups.

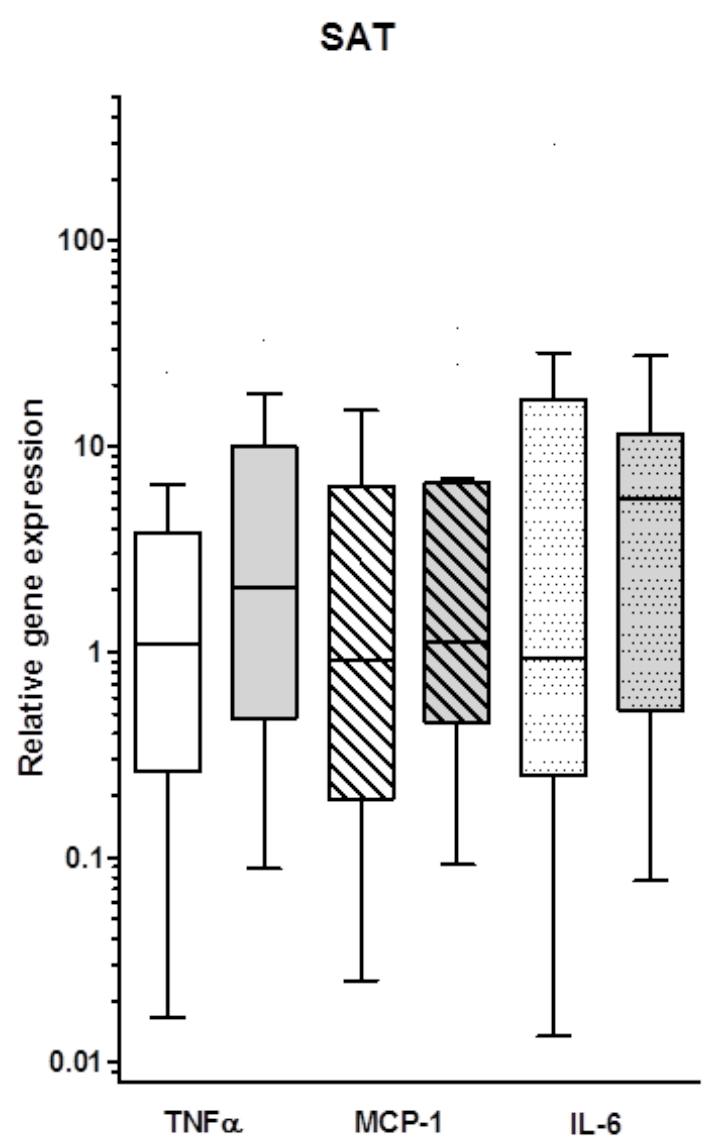

Fig. 1. Relative gene expression of $T N F a, M C P-1$, and $I L-6$ in SAT of living kidney donors $(n=35)$ and patients with PAD $(n=24)$. Comparison of gene expression between LKDs and patients is presented as Turkey boxplot. Grey bars represent patients with PAD, white bars represent LKDs. TNFa - tumor necrosis factor-alpha; MCP-1 - monocyte chemoattractant protein 1 (stripes); IL-6 - interleukin 6 (dots). 
VAT

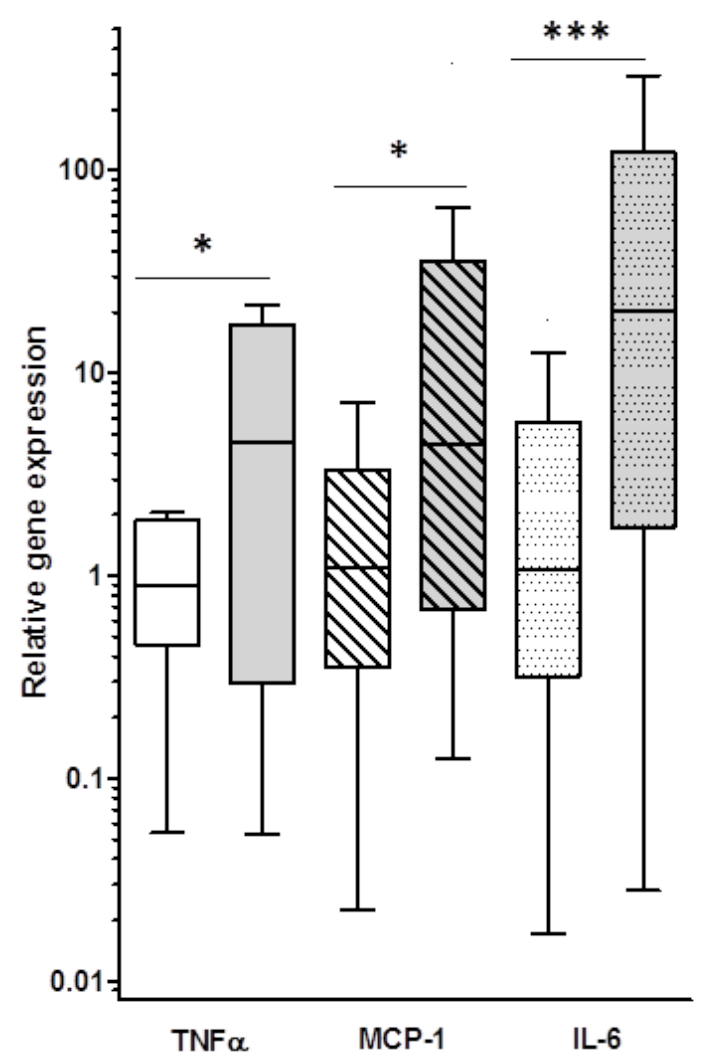

Fig. 2. Relative gene expression of TNFa, MCP-1, and IL-6 in VAT of living kidney donors $(n=35)$ and patients with PAD $(n=24)$. Comparison of gene expression between LKDs and patients is presented as Turkey boxplot. Grey bars represent patients with PAD, white bars represent LKDs. TNFa - tumor necrosis factor-alpha; MCP-1 - monocyte chemoattractant protein 1 (stripes); IL-6 - interleukin 6 (dots); * p<0.05; $* * * \mathrm{p}<0.001$.

When analyzing the gene expression of the PAD patient group from the point of view of severity of the disease, measured by the degree of arterial stenosis and blockade, no significant difference in the gene expression of TNF $\alpha$, MCP-1 as well as IL-6 was found, with the implication being that, within the rather small group of PAD patients, there were no differences in gene expression between mild or severe atherosclerotic lesions of peripheral arteries.

A comparison of LKD smokers and non-smokers did not reveal any differences.

\section{Discussion}

The main result of our study is documented higher gene expression of pro-inflammatory cytokines in AT in consistent with the blood plasma levels of pro-inflammatory cytokines in the PAD group compared to healthy individuals (living kidney donors). This

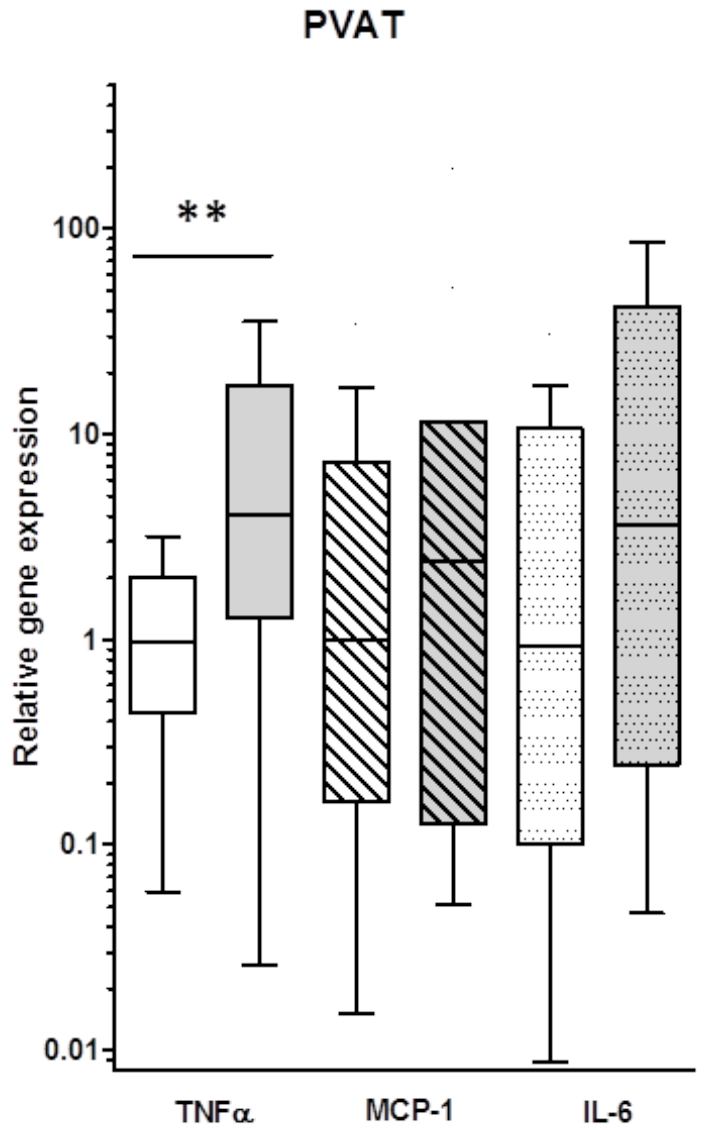

Fig. 3. Relative gene expression of TNFa, MCP-1, and IL-6 in PVAT of living kidney donors $(n=35)$ and patients with PAD $(n=24)$. Comparison of gene expression between LKDs and patients is presented as Turkey boxplot. Grey bars represent patients with PAD, white bars represent LKDs. TNFa - tumor necrosis factor-alpha; MCP-1 - monocyte chemoattractant protein 1 (stripes); IL-6 - interleukin 6 (dots); ** p<0.01.

finding could support the importance of AT in the development of atherosclerosis, in particular the role of VAT in this process. It has been repeatedly proved that the main changes affecting the pro-inflammatory status in AT are associated with monocyte/macrophage infiltration and pro-inflammatory changes of long-lasting residents within macrophage populations (Suganami and Ogawa 2010, Chawla et al. 2011). These pathological changes produce not only a shift towards decreased sensitivity of AT to insulin but also induce further changes within the whole body (Suganami and Ogawa 2010). It is still not clear if pro-inflammatory status is the result of insulin resistance or the other way round (Blüher 2016). Whichever way it is, a role of AT macrophages in atherosclerotic changes in the arterial wall (Suganami and Ogawa 2010, Alexander et al. 2003) has been definitely confirmed. The bulk of data describing these pro-atherosclerotic changes comes from animal models but adequate information about this pro-atherogenic 
process in humans is still lacking. Generally, there is little information about the inflammatory activity of human AT of non-obese individuals.

To assess the role of the indirect effect of AT on the general pro-inflammatory status in humans, we analyzed the expression of three pro-inflammatory genes produced both by whole AT of healthy individuals (LKDs) and patients with PAD. The difference in the proinflammatory status of both groups was documented by higher concentrations of TNF $\alpha$ and hsCRP in the blood of patients.

Our data of increased expression of pro-inflammatory cytokines in PAD patients are essentially consistent with the data of Cheng et al. (2008). They found higher expression of IL-6 and TNF $\alpha$ in the PVAT and VAT of patients with coronary artery disease compared to those without coronary artery disease. The differences in the gene expression of visceral fat of patients with coronary artery disease reported by Cheng et al. (2008) are very similar to our data whereas, in PVAT, we documented a significant difference only in $\mathrm{TNF} \alpha$. It should be stressed that this similarity is present despite the very different design of both studies.

While, in our group of PAD patients, the expression of all three genes and all three types of AT was in mean data higher compared to that of LKDs, statistically significant differences were found only in all three genes in VAT, and TNF $\alpha$ in PVAT. The differences were present although the number of macrophages infiltrating VAT and PVAT was no higher (Figs 1, 2 and $3)$. The absence of a change in the gene expression in SAT in our study is in line with data presented by Gerhard et al. (2014). Also Bilgic Gazioglu et al. (2015) reported higher gene expression of the TNF $\alpha$ gene in patients with coronary artery disease compared to controls but their data may have been biased by obesity of patients. When summarizing the differences in gene expression between LKDs and PAD patients it should be stressed that we did not find any effect of smoking or age on all three genes in either group.

Our data documenting an important role of VAT and PVAT in atherosclerosis development are in agreement with results of tissue cultures reported by Zdychova et al. (2012) and the findings of one experimental model (Chatterjee et al. 2009).

Certainly, one of the limitations of our data is the highly significant difference between the groups in age. When comparing younger and older individuals within the group of LKDs (cut-off point 50 years) we did not find any difference either in the blood plasma cytokine concentration or in the gene expression of any of the genes in any AT. The absence of any age-dependent difference is not surprising as we observed (Kralova Lesna et al. 2015b) no correlation with pro-inflammatory macrophages in the AT of male LKDs, and a higher number of infiltrated macrophages population was found in women which increases after menopause (only 5 of the whole LKD group) (Králová et al. 2015).

In summary, the increase in pro-inflammatory genes in VAT is likely due to pro-inflammatory polarization of macrophages resident in this AT of patients with advanced atherosclerosis. The anticipated pro-inflammatory changes in VAT are in agreement with intra-vessel concentrations of the two pro-inflammatory markers, TNF $\alpha$ and hsCRP. Our data thus confirm the importance of AT in the process of atherogenesis. However, a more substantial question is whether or not the pro-inflammatory changes in AT, as documented in the affected group, were due to the pathology or if the pro-inflammatory status had existed long before in individuals prone to atherosclerosis development.

\section{Conflict of Interest}

There is no conflict of interest.

\section{Acknowledgements}

This study was supported by the project (Ministry of Health, Czech Republic) for development of research organization 00023001 (Institute for Clinical and Experimental Medicine, Prague, Czech Republic) institutional support.

\section{References}

ALEXANDER CM, LANDSMAN PB, TEUTSCH SM, HAFFNER SM: NCEP-defined metabolic syndrome, diabetes, and prevalence of coronary heart disease among NHANES III participants age 50 years and older. Diabetes 52: 1210-1214, 2003.

ALEXOPOULOS N, KATRITSIS D, RAGGI P: Visceral adipose tissue as a source of inflammation and promoter of atherosclerosis. Atherosclerosis 233: 104-112, 2014. 
BILGIC GAZIOGLU S, AKAN G, ATALAR F, ERTEN G: PAI-1 and TNF- $\alpha$ profiles of adipose tissue in obese cardiovascular disease patients. Int J Clin Exp Pathol 8: 15919-15925, 2015.

BLÜHER M: Adipose tissue inflammation: a cause or consequence of obesity-related insulin resistance? Clin Sci (Lond) 130: 1603-1614, 2016.

BRITTON KA, PEDLEY A, MASSARO JM, CORSINI EM, MURABITO JM, HOFFMANN U, FOX CS: Prevalence, distribution, and risk factor correlates of high thoracic periaortic fat in the Framingham Heart Study. $J$ Am Heart Assoc 1: e004200, 2012.

BROWN NK, ZHOU Z, ZHANG J, ZENG R, WU J, EITZMAN DT, CHEN YE, CHANG L: Perivascular adipose tissue in vascular function and disease: a review of current research and animal models. Arterioscler Thromb Vasc Biol 34: 1621-1630, 2014.

CHANG L, MILTON H, EITZMAN DT, CHEN YE: Paradoxical roles of perivascular adipose tissue in atherosclerosis and hypertension. Circ J 77: 11-18, 2013.

CHATTERJEE TK, STOLL LL, DENNING GM, HARRELSON A, BLOMKALNS AL, IDELMAN G, ROTHENBERG FG, NELTNER B, ROMIG-MARTIN SA, DICKSON EW, RUDICH S, WEINTRAUB NL: Proinflammatory phenotype of perivascular adipocytes: influence of high-fat feeding. Circ Res 104: 541-549, 2009.

CHAWLA A, NGUYEN KD, GOH YPS: Macrophage-mediated inflammation in metabolic disease. Nat Rev Immunol 11: 738-749, 2011.

CHENG KH, CHU CS, LEE KT, LIN TH, HSIEH CC, CHIU CC, VOON WC, SHEU SH, LAI WT: Adipocytokines and proinflammatory mediators from abdominal and epicardial adipose tissue in patients with coronary artery disease. Int J Obes (Lond) 32: 268-274, 2008.

FOX CS, MASSARO JM, HOFFMANN U, POU KM, MAUROVICH-HORVAT P, LIU CY, VASAN RS, MURABITO JM, MEIGS JB, CUPPLES LA, D'AGOSTINO RB, O’DONNELL CJ: Abdominal visceral and subcutaneous adipose tissue compartments: association with metabolic risk factors in the Framingham Heart Study. Circulation 116: 39-48, 2007.

FUNAHASHI T, NAKAMURA T, SHIMOMURA I, MAEDA K, KURIYAMA H, TAKAHASHI M, ARITA Y, KIHARA S, MATSUZAWA Y: Role of adipocytokines on the pathogenesis of atherosclerosis in visceral obesity. Intern Med 38: 202-206, 1999.

GERHARD GS, STYER AM, STRODEL WE, ROESCH SL, YAVOREK A, CAREY DJ, WOOD GC, PETRICK AT, GABRIELSEN J, IBELE A, BENOTTI P, ROLSTON DD, STILL CD, ARGYROPOULOS G: Gene expression profiling in subcutaneous, visceral, and epigastric adipose tissues of patients with extreme obesity. Int J Obes (Lond) 38: 371-378, 2014.

HARDMAN RL, JAZAERI O, YI J, SMITH M, GUPTA R: Overview of classification systems in peripheral artery disease. Semin Intervent Radiol 31: 378-388, 2014.

JONAS MI, KURYLOWICZ A, BARTOSZEWICZ Z, LISIK W, JONAS M, WIERZBICKI Z, CHMURA A, PRUSZCZYK P, PUZIANOWSKA-KUZNICKA M: Interleukins 6 and 15 levels are higher in subcutaneous adipose tissue, but obesity is associated with their increased content in visceral fat depots. Int J Mol Sci 16: 25817-25830, 2015.

KANDA H, TATEYA S, TAMORI Y, KOTANI K, HIASA KI, KITAZAWA R, KITAZAWA S, MIYACHI H, MAEDA S, EGASHIRA K, KASUGA M: MCP-1 contributes to macrophage infiltration into adipose tissue, insulin resistance, and hepatic steatosis in obesity. J Clin Invest 116: 1494-1505, 2006.

KLEINBONGARD P, HEUSCH G, SCHULZ R: TNF $\alpha$ in atherosclerosis, myocardial ischemia/reperfusion and heart failure. Pharmacol Ther 127: 295-314, 2010.

KRÁLOVÁ A, KRÁLOVÁ LESNÁ I, FRONĚK J, ČEJKOVÁ S, SEKERKOVÁ A, JANOUŠEK L, THIEME F, STŘÍŽ I, ŽDYCHOVÁ J, POLEDNE R: Macrophage phenotypes in the adipose tissue of postmenopausal women. Physiol Res 64 (Suppl 3): S427-S433, 2015.

KRÁLOVÁ LESNÁ I, POLEDNE R, FRONEK J, KRÁLOVÁ A, SEKERKOVÁ A, THIEME F, PITHA J: Macrophage subsets in the adipose tissue could be modified by sex and the reproductive age of women. Atherosclerosis 241: 255-258, 2015a. 
KRALOVA LESNA I, TONAR Z, MALEK I, MALUSKOVA J, NEDOROST L, PIRK J, PITHA J, LANSKA V, POLEDNE R: Is the amount of coronary perivascular fat related to atherosclerosis? Physiol Res 64 (Suppl 3): S435-S443, 2015b.

LITVINOVA L, ATOCHIN D, VASILENKO M, FATTAKHOV N, ZATOLOKIN P, VAYSBEYN I, KIRIENKOVA E: Role of adiponectin and proinflammatory gene expression in adipose tissue chronic inflammation in women with metabolic syndrome. Diabetol Metab Syndr 6: 137, 2014.

PFAFFL MW: A new mathematical model for relative quantification in real-time RT-PCR. Nucleic Acids Res 29: e45, 2001.

POU KM, MASSARO JM, HOFFMANN U, VASAN RS, MAUROVICH-HORVAT P, LARSON MG, KEANEY JF, MEIGS JB, LIPINSKA I, KATHIRESAN S, MURABITO JM, O’DONNELL CJ, BENJAMIN EJ, FOX CS: Visceral and subcutaneous adipose tissue volumes are cross-sectionally related to markers of inflammation and oxidative stress: The Framingham Heart Study. Circulation 116: 1234-1241, 2007.

RIDKER PM, CUSHMAN M, STAMPFER MJ, TRACY RP, HENNEKENS CH: Inflammation, aspirin, and the risk of cardiovascular disease in apparently healthy men. $N$ Engl J Med 336: 973-979, 1997.

SADASHIV, TIWARI S, GUPTA V, PAUL BN, KUMAR S, CHANDRA A, DHANANJAI S, NEGI MPS, GHATAK A: IL-6 gene expression in adipose tissue of postmenopausal women and its association with metabolic risk factors. Mol Cell Endocrinol 399: 87-94, 2015.

SOPASAKIS VR, NAGAEV I, SMITH U: Cytokine release from adipose tissue of nonobese individuals. Int $J$ Obes (Lond) 29: 1144-1147, 2005.

SUGANAMI T, OGAWA Y: Adipose tissue macrophages: their role in adipose tissue remodeling. $J$ Leukoc Biol 88: 33-39, 2010.

VAGUE J: The degree of masculine differentiation of obesities. Am J Clin Nutr 4: 20-34, 1956.

ZDYCHOVA J, KRALOVA LESNA I, MALUSKOVA J, JANOUSEK L, CAHOVA M, KAZDOVA L: Comparison of gene expression of epicardial and visceral adipocytes with regard to the differentiation stage. Neuro Endocrinol Lett 33 (Suppl 2): 93-97, 2012.

ZUK PA, ZHU M, MIZUNO H, HUANG J, FUTRELL JW, KATZ AJ, BENHAIM P, LORENZ HP, HEDRICK MH: Multilineage cells from human adipose tissue: implications for cell-based therapies. Tissue Eng 7: 211-228, 2001. 